\title{
Nutrition
} advice for oral health

Latest research from the British Dental Association (BDA) and Wrigley Oral Healthcare in Action (OHA) has found that nutrition is now a core factor for dentists when assessing their patients' oral health.

Results from the survey, which was carried out at the 2006 BDA Conference, show that over $40 \%$ of dentists are seeing over 21 patients per week for whom nutritional advice would help improve their oral care routine.

Just over $60 \%$ of the dentists surveyed felt they did not have enough information to offer advice on this subject to their patients. Nutritionist Penny Hunking said, 'Nutrition and a healthy balanced diet is extremely important in the care of our mouth, teeth and gums. There is no doubt that poor diet can lead to poor oral health and it is essential for dentists to have this information to hand so they know how best to advise their patients. With today's busy lifestyles people are eating more convenience food and snacks, often with high sugar contents. They need advice on how a good diet can help maintain oral health.'

Wrigley OHA randomly selected a dentist

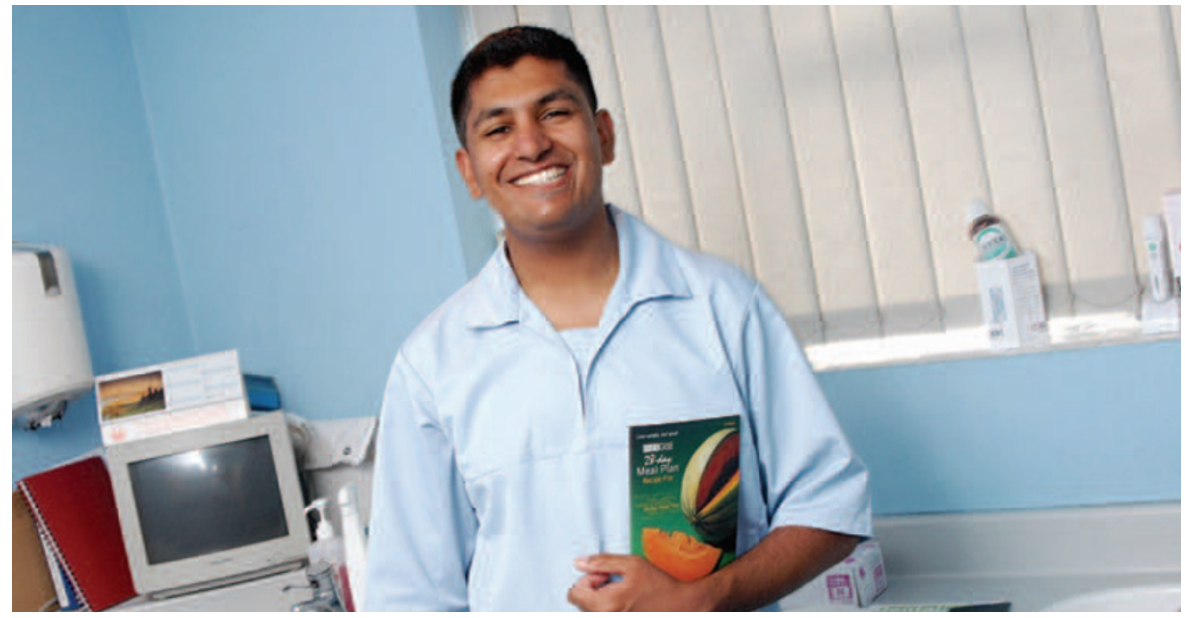

Dentist Kevel Shah from Amwell Street Dental Practice in Hertfordshire.

who signed up to the Wrigley OHA programme at the BDA Conference to benefit from a session with Penny at their practice. Penny ran a session on diet and nutrition, in particular their impact on oral health, with winner Kevel Shah and his team at Amwell Street Dental Practice in Hertfordshire.

The aim of the Wrigley OHA Programme is to help promote better oral healthcare and the company provides patients and professionals with practical resources and materials on oral care in a way that is relevant to today's lifestyle and needs.

To find out more about the programme visit www.betteroralhealth.info or call free on 08000564563 .

\section{Undergraduate DCPs rewarded}

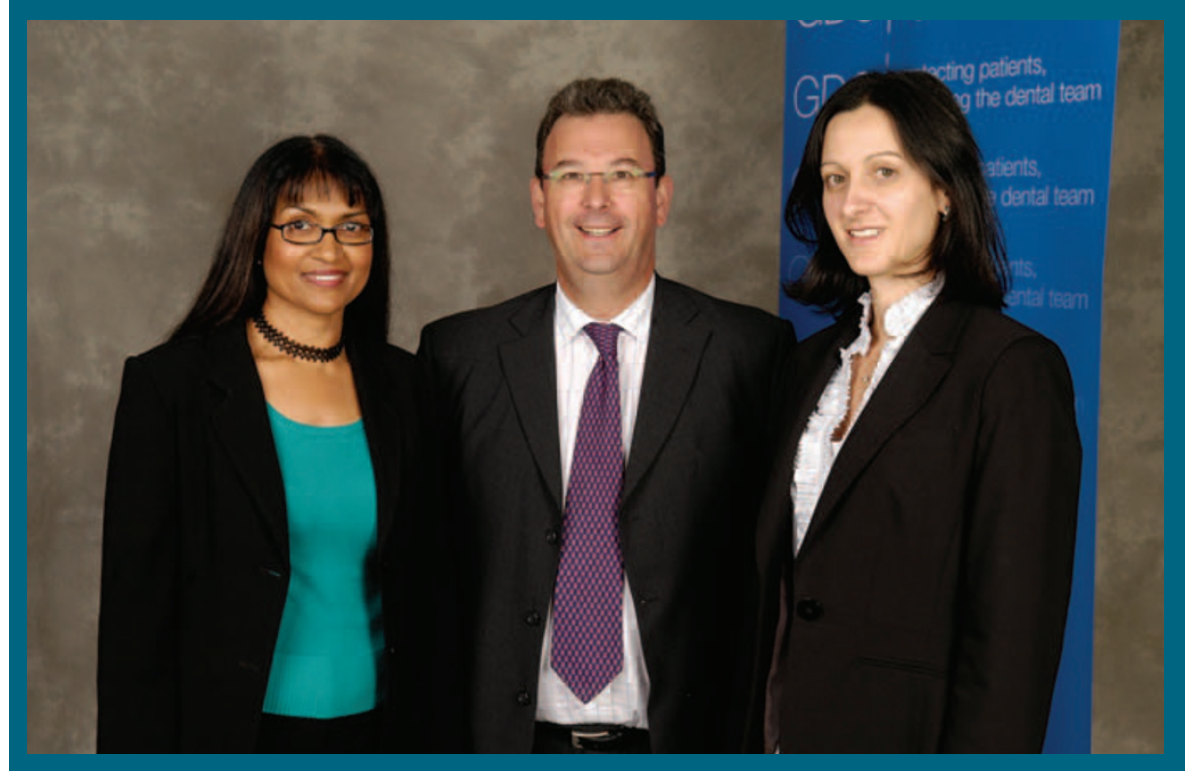

From left to right: Hasmita Madhani, Hew Mathewson and Andrijana Paratusic.

The General Dental Council has announced the 2006 winners of the GDC Prize for Professionalism. Amongst the winners are
Dental Hygienist Andrijana Paratusic, and Combined Hygienist \& Therapist Hasmita Madhani of the School of Dental Hygiene and Dental Therapy, Eastman Dental Hospital, London.

The Prize for Professionalism gives the GDC an opportunity to recognise the achievements of student dental professionals in the UK. It is an annual prize, sponsored by the GDC Charitable Trust, and makes a financial award to students who have demonstrated professionalism in areas such as patient care, clinical governance, team working, communication skills, reliability, integrity and knowledge.

Each UK dental school, school of dental hygiene and school of dental therapy with undergraduates nominates a winner from each of the courses they run. The prize is $£ 250$ for dentistry students; $£ 150$ for dental therapy students and combined dental therapy and hygiene students; and $£ 100$ for dental hygiene students (the prize money corresponds to the length of the study programmes). To see the full list of winners visit www.gdc-uk.org. 